\title{
MitraClip patient selection: inclusion and exclusion criteria for optimal outcomes
}

\author{
Mario Gössl, Paul Sorajja \\ Valve Science Center, Minneapolis Heart Institute Foundation, Abbott Northwestern Hospital, Minneapolis, MN, USA \\ Correspondence to: Mario Gössl, MD, PhD. Director, Transcatheter Research and Education, Valve Science Center, Minneapolis Heart Institute \\ Foundation, Abbott Northwestern Hospital, 920 East 28th Street, Suite 300, Minneapolis, MN, USA. Email: Mario.Goess1@Allina.com.
}

Edge-to-edge repair with the percutaneous MitraClip technology has changed the landscape for patients with symptomatic, severe degenerative mitral valve regurgitation who are at prohibitive surgical risk. While the results of randomized controlled trials of MitraClip therapy in patients with functional mitral valve regurgitation are still pending, single center experiences as well as registry data generally support the realworld application of the MitraClip therapy. In the majority of individuals treated with MitraClip, complete or near-complete relief of mitral regurgitation occurs, with results approaching the effectiveness of open surgery. This perspective summarizes the data, with a focus on current selection criteria of percutaneous MitraClip edge-to-edge repair that can optimize clinical outcomes.

Keywords: MitraClip; functional mitral valve regurgitation (FMR); degenerative mitral valve regurgitation (DMR); inclusion exclusion criteria

Submitted Jul 03, 2018. Accepted for publication Aug 08, 2018.

doi: 10.21037/acs.2018.08.04

View this article at: http://dx.doi.org/10.21037/acs.2018.08.04

Edge-to-edge repair with the percutaneous MitraClip technology has changed the landscape for patients with symptomatic, severe mitral valve regurgitation, with already $>60,000$ procedures performed worldwide. The optimal outcome of a MitraClip intervention can be expected in a patient at prohibitive surgical risk with degenerative mitral valve regurgitation (DMR) between the P2/A2 scallops and an expected reduction of the mitral valve regurgitation (MR) to $\leq 2+$, which is achieved in $>95 \%$ of cases.

In the initial experience of $>500$ patients treated with commercial transcatheter mitral valve repair in the USA (1), the 30-day outcome data showed that the A2-P2 location was targeted in $78 \%$ of cases, with $37 \%$ of cases requiring $>1$ device. The location of clip implantation was shown to be critical for clinical success. Univariate analysis suggests, a MitraClip in the A2/P2 location was associated with higher post-implantation success, as indicated by an $M R$ grade $\leq 2$ [odds ratio (OR) vs. other location: 2.29; $95 \%$ confidence interval (CI): 1.20 to $4.36 ; \mathrm{P}=0.02$ ]. For the primary composite outcome (i.e., residual MR grade $\leq 2$, no conversion to cardiac surgery and no in-hospital mortality), clip implantation at $\mathrm{A} 2 / \mathrm{P} 2$ remained significant in multivariate models (OR: 2.36; $95 \%$ CI: 1.26 to 4.46; $\mathrm{P}=0.008)$. Of note, in this US-registry only $9 \%$ of patients had functional mitral regurgitation (FMR), showing a strict adherence of US operators to inclusion/exclusion criteria as dictated by the directions for use (DFU) of the MitraClip device (Table 1).

While the A2/P2 pathology in DMR may be considered ideal anatomy for a MitraClip intervention, the most common clinical indication worldwide is functional MR (FMR), present in $60 \%$ to $80 \%$ of case (2). Multiple ongoing trials are evaluating the role of MitraClip in FMR. These include a multicenter, randomized control study to assess Mitral vAlve reconsTrucTion for advancEd Insufficiency of Functional or iscHemic ORigiN (MATTERHORN, NCT02371512), the Cardiovascular Outcomes Assessment of the MitraClip Percutaneous Therapy for Heart Failure Patients With Functional Mitral Regurgitation (COAPT, NCT01626079), the randomized Study of the MitraClip Device in Heart Failure Patients with Clinically Significant Functional Mitral Regurgitation 


\begin{tabular}{|c|c|}
\hline \multirow{3}{*}{$\begin{array}{l}\text { Significant symptomatic mitral regurgitation }(\mathrm{MR} \geq 3+) \text { due to } \\
\text { primary abnormality of the mitral apparatus [degenerative } \mathrm{MR} \text { ] } \\
\text { in patients who have been determined to be at prohibitive } \\
\text { risk for mitral valve surgery by a heart team, which includes } \\
\text { a cardiac surgeon experienced in mitral valve surgery and a } \\
\text { cardiologist experienced in mitral valve disease, and in whom } \\
\text { existing comorbidities would not preclude the expected } \\
\text { benefit from reduction of the mitral regurgitation }\end{array}$} & $\begin{array}{l}\text { Patients who cannot tolerate procedural anticoagulation or post } \\
\text { procedural anti-platelet regimen }\end{array}$ \\
\hline & Active endocarditis of the mitral valve \\
\hline & Rheumatic mitral valve disease \\
\hline
\end{tabular}

(RESHAPE) and the Multicenter Study of Percutaneous Mitral Valve Repair MitraClip Device in Patients With Severe Secondary Mitral Regurgitation [MITRA-FR, NCT01920698 (3)] randomized trials. These trials compare the percutaneous edge-to-edge repair with optimal medical therapy (COAPT, RESHAPE, MITRA-FR) or surgery (MATTERHORN) in FMR patients and should help to clarify the role and indication of percutaneous MitraClip edge-to-edge repair in these patients.

Single center reports have evaluated outcomes of patients with versus without "EVEREST criteria" (Table 2), which had been used to enroll patients into the pre-clinical studies. Overall, these studies have shown comparable outcomes, but higher rates of recurrent symptomatic MR and need for more re-interventions, mainly because of functional etiology or complex valve pathology (5). Few prospective observational registries have reported direct outcome comparisons between FMR and DMR patients treated with MitraClip (2,6-11). In a recent meta-analysis of these studies, Chiarito et al. showed that mitral valve reintervention at 1 year was at a significantly lower rate in patients with FMR compared with those with DMR (4\% vs. $10 \%$, FMR vs. DMR, respectively; RR 0.60; 95\% CI: 0.38 to $0.97 ; \mathrm{P}=0.04$ ) without a significant difference in mortality between the two groups (18\% vs. 14\%, FMR vs. DMR, respectively; RR 1.26; $95 \%$ CI: 0.90 to $1.77 ; \mathrm{P}=0.18$ ). Both, DMR and FMR patients showed an acceptable $15 \%$ recurrence of $>2+M R$. While incomplete, these data should be considered successful in the context of historically high surgical failure rates after surgical valve repair for FMR patients (between 14-66\%) (12-14). Notably, FMR patients presented more frequently in severe heart failure (i.e., NYHA III/IV) and were re-hospitalized for heart failure more often at 1-year follow-up, despite no significant difference in the recurrence of $M R \geq 2+$ between the two groups (15). These results underscore the clinical dilemma of treating patients with severe functional MR, without directly addressing the underlying valvular cardiomyopathy.

\section{Does the degree of MR matter?}

The degree of MR going into the procedure can affect the short- and long-term outcome after the implantation. The Transcatheter Valve Therapy (TVT) registry data demonstrated that baseline MR degree grade impacts the success as defined by post-procedural $M R \leq 2$ (OR per increasing grade: $0.66 ; 95 \%$ CI: 0.47 to $0.93 ; \mathrm{P}=0.02$ ). In addition, the presence of multiple jets of MR can negatively impact short- and long-term outcomes of MitraClip due to the high likelihood of requiring multiple clips to achieve an adequate reduction of MR (16). On the other hand, there are reports cautioning against a single clip strategy, suggesting increased risk of residual and recurrent MR (17).

\section{Ejection fraction-how low is too low?}

Data from the German transcatheter mitral valve interventions registry (TRAMI, $>800$ patients) show that an ejection fraction of $<30 \%$ is an independent predictor of 1-year mortality (18). Similarly, Giannini et al. have 


\begin{tabular}{|c|c|}
\hline $\begin{array}{l}\text { Moderate-severe }(3+) \text { or severe }(4+) \text { chronic MR } \\
\text { and }\end{array}$ & Acute myocardial infarction in the prior 12 weeks of the intended treatment \\
\hline $\begin{array}{l}\text { Symptomatic with }>25 \% \text { left ventricular ejection } \\
\text { fraction and left ventricular end-systolic diameter } \\
\leq 55 \mathrm{~mm} \text { or }\end{array}$ & The need for any other cardiac surgery \\
\hline Asymptomatic with one or more of the following: & $\begin{array}{l}\text { Any endovascular therapeutic interventional or surgical procedure performed within } \\
30 \text { days prior }\end{array}$ \\
\hline (I) LVEF $25 \%$ to $60 \%$ & Ejection fraction b25\%, and/or end-systolic dimension $>55 \mathrm{~mm}$ \\
\hline (II) LVESD $\geq 40 \mathrm{~mm}$ & $\mathrm{MV}$ orifice area $<4.0 \mathrm{~cm}^{2}$ \\
\hline $\begin{array}{l}\text { Candidate for MV repair or replacement surgery, } \\
\text { including cardiopulmonary bypass }\end{array}$ & $\begin{array}{l}\text { If leaflet tethering is present, coaptation depth }>11 \mathrm{~mm} \text {, or vertical coaptation length } \\
\text { is }<2 \mathrm{~mm}\end{array}$ \\
\hline \multirow{6}{*}{$\begin{array}{l}\text { The primary regurgitant jet originates from } \\
\text { malcoaptation of the } \mathrm{A} 2 \text { and } \mathrm{P} 2 \text { scallops of } \\
\text { the MV. If a secondary jet exists, it must be } \\
\text { considered clinically insignificant }\end{array}$} & $\begin{array}{l}\text { Leaflet anatomy that may preclude clip implantation, proper clip positioning on the } \\
\text { leaflets, or sufficient reduction in MR. This may include the following: }\end{array}$ \\
\hline & Evidence of calcification in the grasping area of the A2 and/or P2 scallops \\
\hline & Presence of a significant cleft of $\mathrm{A} 2$ or $\mathrm{P} 2$ scallops \\
\hline & More than 1 anatomic criteria dimensionally near the exclusion limits \\
\hline & History of or active endocarditis or rheumatic heart disease \\
\hline & History of atrial septal defect or patent foramen ovale associated with clinical symptoms \\
\hline
\end{tabular}

demonstrated that reverse left ventricular (LV) remodeling after percutaneous edge-to-edge repair can more likely be expected in patients without advanced congestive heart failure (i.e., left ventricular ejection fraction $>30 \%$ ) and without severe left ventricular dilation (left ventricular enddiastolic diameter $<70 \mathrm{~mm}$, left ventricular end-diastolic volume $<200 \mathrm{~mL}$ ) (19). Moreover, it is well known that left ventricular dysfunction, as assessed by echocardiography prior to repair or replacement, is often underestimated in patients with severe MR because of a systolic unloading resulting from low-resistance ejection to the left atrium (20). Current clinical trials have excluded most patients with ejection fraction $<30 \%$, and practice guidelines also caution against open surgery for patients with such severe dysfunction. While MitraClip can palliate symptoms in patients with severe dysfunction and even salvage those in cardiogenic shock, the long-term survival effect of such treatment needs further study.

\section{Does the valve area and calcification matter?}

The TVT registry data did not show any significant association of pre-procedural mitral valve area $<4 \mathrm{~cm}^{2}$, mitral annular calcification, or mitral valve gradient 
$>4 \mathrm{mmHg}$ with procedural success (1), even though these findings were evident in $\sim 20 \%$ of patients. In carefully selected patients with these abnormalities, MitraClip can be performed successfully. Notably, the greatest reduction in mitral valve area with MitraClip occurs when clip placement is performed in the center of the valve (i.e., A2-P2), as this position leads to the greatest reduction in the septal-lateral dimension of the mitral valve (i.e., up to $50 \%$ reduction in area). When MR treatment occurs away from this area (i.e., A1-P1 or A3-P3), treatment may be successful but other studies have shown that optimal results are less likely in patients with even borderline elevated mitral gradient pre-procedure and mitral annular calcification (16). In our experience, we have not found value in the use of MitraClip in patients with either rheumatic or radiation-induced heart disease and overall support the best practice of MitraClip therapy for patients with a mitral valve area $\geq 4 \mathrm{~cm}^{2}$.

\section{Other applications}

MitraClip therapy has also successfully been applied in other applications, such as hypertrophic obstructive cardiomyopathy (HOCM) (21), as well as in the treatment of recurrent mitral valve regurgitation after mitral valve ring repair (22). For HOCM, MitraClip limits the systolic anterior motion of the anterior mitral valve leaflet, thereby reducing left ventricular outflow obstruction, while also addressing the dynamic mitral regurgitation. Early experience has been positive, though caution must be used in these patients due to their relatively small mitral annuli. Similarly, relatively small mitral annuli are also a concern in patients with prior surgery, due to the frequent use of down-sized annuloplasty bands or rings. MitraClip in postsurgical patients is possible, provided there is suitable tissue for anchoring-a challenge when leaflet resection has been undertaken. Although the DFU for MitraClip excludes its use in patients with femoral or caval thrombi, a case report by Barbin et al. shows that it can be done if absolutely necessary and in the context of lack of alternative treatment options (23).

\section{Importance of a multidisciplinary heart team approach}

MITRA-FR (3), RESHAPE and COAPT will clarify the role of MitraClip vs. optimal guideline-directed medical therapy alone in patients with functional mitral valve regurgitation. While we await the results of these important trials, we consider the addition of an advanced heart failure specialist to the heart team essential. In concert with a cardiovascular surgeon and an implanting interventional cardiologist, this team can ascertain that the patient with functional mitral valve regurgitation receives the optimal therapy for the primary left ventricular pathophysiology. The heart team should therefore always carefully weigh risks and benefits as well as the likelihood of adequate repair success between MitraClip and surgical repair. Some may advocate a 'give MitraClip a try first' strategy, but this approach must be tempered greatly when the patient is operable and the chance of complete MR relief with repair-surgery is high. Indeed, most of the patients with failed MitraClip implantation will require a mitral valve replacement (24).

\section{Conclusions}

MitraClip presents an excellent therapeutic option for patients with mitral valve regurgitation who are at prohibitive risk for a surgical repair or replacement. Ongoing randomized controlled trials in patients with functional mitral valve regurgitation will provide further insight into the role of this therapy in comparison to medical therapy or surgery. It remains crucial to select the best-suited patients for this therapy through an advanced heart team decision-making process. Current inclusion and exclusion criteria have consistently been shown to be key in short- and long-term procedural success.

\section{Acknowledgements}

None.

\section{Footnote}

Conflicts of Interest: The authors have no conflicts of interest to declare.

\section{References}

1. Sorajja P, Mack M, Vemulapalli S, et al. Initial Experience With Commercial Transcatheter Mitral Valve Repair in the United States. J Am Coll Cardiol 2016;67:1129-40.

2. Whitlow PL, Feldman T, Pedersen WR, et al. Acute and 12-month results with catheter-based mitral valve leaflet repair: the EVEREST II (Endovascular Valve Edgeto-Edge Repair) High Risk Study. J Am Coll Cardiol 2012;59:130-9. 
3. Obadia JF, Armoiry X, Iung B, et al. The MITRA-FR study: design and rationale of a randomised study of percutaneous mitral valve repair compared with optimal medical management alone for severe secondary mitral regurgitation. EuroIntervention 2015;10:1354-60.

4. Mauri L, Garg P, Massaro JM, et al. The EVEREST II Trial: design and rationale for a randomized study of the evalve mitraclip system compared with mitral valve surgery for mitral regurgitation. Am Heart J 2010;160:23-9.

5. Lesevic H, Karl M, Braun D, et al. Long-Term Outcomes After MitraClip Implantation According to the Presence or Absence of EVEREST Inclusion Criteria. Am J Cardiol 2017;119:1255-61.

6. Maisano F, Franzen O, Baldus S, et al. Percutaneous mitral valve interventions in the real world: early and 1-year results from the ACCESS-EU, a prospective, multicenter, nonrandomized post-approval study of the MitraClip therapy in Europe. J Am Coll Cardiol 2013;62:1052-61.

7. Braun D, Lesevic H, Orban M, et al. Percutaneous edge-to-edge repair of the mitral valve in patients with degenerative versus functional mitral regurgitation. Catheter Cardiovasc Interv 2014;84:137-46.

8. Chan PH, She HL, Alegria-Barrero E, et al. Real-world experience of MitraClip for treatment of severe mitral regurgitation. Circ J 2012;76:2488-93.

9. Grasso C, Capodanno D, Scandura S, et al. One- and twelvemonth safety and efficacy outcomes of patients undergoing edge-to-edge percutaneous mitral valve repair (from the GRASP Registry). Am J Cardiol 2013;111:1482-7.

10. Nickenig G, Estevez-Loureiro R, Franzen O, et al. Percutaneous mitral valve edge-to-edge repair: in-hospital results and 1-year follow-up of 628 patients of the 20112012 Pilot European Sentinel Registry. J Am Coll Cardiol 2014;64:875-84.

11. Rudolph V, Lubos E, Schluter M, et al. Aetiology of mitral regurgitation differentially affects 2 -year adverse outcomes after MitraClip therapy in high-risk patients. Eur J Heart Fail 2013;15:796-807.

12. Hung J, Papakostas L, Tahta SA, et al. Mechanism of recurrent ischemic mitral regurgitation after annuloplasty: continued LV remodeling as a moving target. Circulation 2004;110:III85-90.

13. Grayburn PA, Foster E, Sangli C, et al. Relationship between the magnitude of reduction in mitral regurgitation severity and left ventricular and left atrial reverse remodeling after MitraClip therapy. Circulation 2013;128:1667-74.

14. Goldstein D, Moskowitz AJ, Gelijns AC, et al. Two-Year
Outcomes of Surgical Treatment of Severe Ischemic Mitral Regurgitation. N Engl J Med 2016;374:344-53.

15. Chiarito M, Pagnesi M, Martino EA, et al. Outcome after percutaneous edge-to-edge mitral repair for functional and degenerative mitral regurgitation: a systematic review and meta-analysis. Heart 2018;104:306-12.

16. Thaden JJ, Malouf JF, Nkomo VT, et al. Mitral Valve Anatomic Predictors of Hemodynamic Success With Transcatheter Mitral Valve Repair. J Am Heart Assoc 2018;7.

17. Buzzatti N, Denti P, La Canna G, et al. Does implantation of a single clip provide reliable durability after transcatheter mitral repair? Eur J Cardiothorac Surg 2017;52:137-42.

18. Puls M, Lubos E, Boekstegers P, et al. One-year outcomes and predictors of mortality after MitraClip therapy in contemporary clinical practice: results from the German transcatheter mitral valve interventions registry. Eur Heart J 2016;37:703-12.

19. Giannini C, Petronio AS, De Carlo M, et al. Integrated reverse left and right ventricular remodelling after MitraClip implantation in functional mitral regurgitation: an echocardiographic study. Eur Heart J Cardiovasc Imaging 2014;15:95-103.

20. Quintana E, Suri RM, Thalji NM, et al. Left ventricular dysfunction after mitral valve repair--the fallacy of "normal" preoperative myocardial function. J Thorac Cardiovasc Surg 2014;148:2752-60.

21. Schafer U, Frerker C, Thielsen T, et al. Targeting systolic anterior motion and left ventricular outflow tract obstruction in hypertrophic obstructed cardiomyopathy with a MitraClip. EuroIntervention 2015;11:942-7.

22. Kanda BS, Jay D, Farivar RS, et al. Leaflet-to-Annuloplasty Ring Clipping for Severe Mitral Regurgitation. JACC Cardiovasc Interv 2016;9:e63-4.

23. Barbin CM, Grayburn PA, Choi JW. Successful MitraClip(R) implantation after angioplasty of a chronic inferior vena cava filter thrombosis. Catheter Cardiovasc Interv 2016;87:1333-7.

24. Elhmidi Y, Voss B, Lange R. Surgical mitral valve intervention following a failed MitraClip procedure. EuroIntervention 2016;12:Y102-6.

Cite this article as: Gössl M, Sorajja P. MitraClip patient selection: inclusion and exclusion criteria for optimal outcomes. Ann Cardiothorac Surg 2018;7(6):771-775. doi: 10.21037/ acs.2018.08.04 